\title{
Spatio-temporal patterns of fecal coliforms in a waterway with high densities of combined sewer overflows: Baseline for an Ecological Lift project on Pleasant Run waterway, Indianapolis, IN (USA)
}

\author{
K. MAZARI ${ }^{1,2}$ AND G.M. FILIPPELLI ${ }^{1,2^{*}}$ \\ 1 Indiana University-Purdue University Indianapolis, \\ Department of \\ Earth Sciences, 723 W. Michigan St., Indianapolis, \\ Indiana 46202-5132, USA (*correspondence: \\ gfilippe@iupui.edu) \\ 2 Environmental Resilient Institute, 717 E 8th St., \\ Bloomington, IN 47408 (kmazari@iu.edu)
}

\begin{abstract}
The Pleasant Run Waterway (PRW) receives contamination from several sources. The main concern from a human health perspective emerges from bacterial pollution originating predominantly from the Combined Sewer Overflow (CSO). Our data (one year monitoring) revealed that some PRW localities significantly exceed EPA standard limit $235 \mathrm{cfu} / 100 \mathrm{~mL}$ for $E$. coli bacteria body exposure, especially during rain/storm events in the combination with higher temperature-this situation is exacerbated by climate change-induced frequent flooding events, thus limiting the opportunity for safe human interaction with the waterway.

We selected six sample sites along the PRW and one control site out of Indianapolis. Additionally, we collected data from White River for one month (July). Beside fecal coliforms, we also monitor water quality parameters, present of some metal and nutrient elements. One of the solutions that can be used prior to technical adjustment seems to be constructed wetlands.
\end{abstract}

